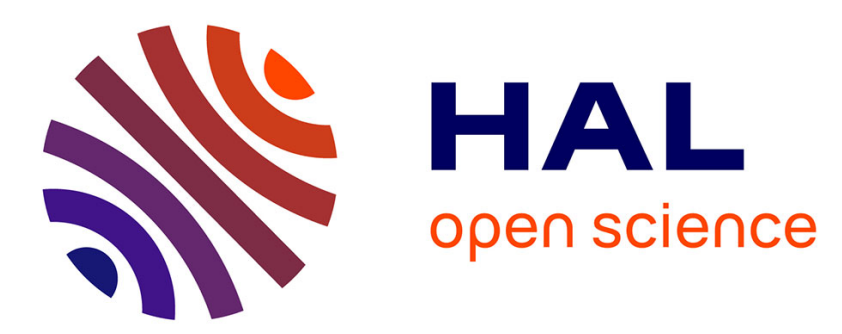

\title{
Collaborative Ontological Engineering of Instructional Design Knowledge for an ITS Authoring Environment
}

\author{
Jacqueline Bourdeau, Riichiro Mizoguchi
}

\section{To cite this version:}

Jacqueline Bourdeau, Riichiro Mizoguchi. Collaborative Ontological Engineering of Instructional Design Knowledge for an ITS Authoring Environment. Cerri, S., Gouardères, G. \& Paraguaçu, F. Intelligent Tutoring Systems, Springer, pp.399-409, 2002, Springer, Heidelberg: Lecture Notes in Computer Science. hal-00190088

\section{HAL Id: hal-00190088 \\ https://telearn.archives-ouvertes.fr/hal-00190088}

Submitted on 23 Nov 2007

HAL is a multi-disciplinary open access archive for the deposit and dissemination of scientific research documents, whether they are published or not. The documents may come from teaching and research institutions in France or abroad, or from public or private research centers.
L'archive ouverte pluridisciplinaire HAL, est destinée au dépôt et à la diffusion de documents scientifiques de niveau recherche, publiés ou non, émanant des établissements d'enseignement et de recherche français ou étrangers, des laboratoires publics ou privés. 


\title{
Collaborative Ontological Engineering of Instructional Design Knowledge for an ITS Authoring Environment
}

\author{
Jacqueline Bourdeau ${ }^{1}$ and Riichiro Mizoguchi ${ }^{2}$ \\ ${ }^{1}$ Télé-université, 4750 Henri-Julien, Montréal (Québec) H2T 3E4 Canada, \\ bourdeau@licef. teluq. uquebec.ca \\ ${ }^{2}$ ISIR, Osaka University, 8-1 Mihogaoka, Ibaraki, Osaka, 567-0047, Japan, \\ miz@ei.sanken.osaka-u.ac.jp
}

\begin{abstract}
Intelligence in an ITS authoring system could rely on content-based engineering of instructional design (ID) knowledge, i.e. based on principles such as conceptualization, standardization and theory -awareness. An ontology based architecture with appropriate ontologies has been proposed for a theoryaware ITS authoring system. Ontological engineering (OE) as a collaborative process jointly conducted by an OE expert and an ID expert is presented as a step on a roadmap towards a theory-aware ITS authoring system.
\end{abstract}

\section{Introduction}

What is (at) the core of Artificial Intelligence and Education (AIED) systems? This has been a question for as long as the field of AIED has come of age, and various answers have been suggested such as curriculum planning [1,2], student modeling $[3,4]$, teaching expertise [5,6], and dialogue modeling [7,8,9], among others. Also suggested was the idea of intelligence implemented all over the periphery of an ITS rather than centralized at a core [10], as is for instance the case of adaptive hypermedia [11].

In this paper, the claim is that declarative knowledge about instruction could be the beating heart of an ITS, where shared intelligence among the designer/author and the authoring environment is the dynamic component for the interactive construction of instructional scenarios and learning environments. The goal of the work presented below is to explore the basic layer needed toward the architecture of an OE based authoring system, as described in [12]. The starting point and the main ideas are therefore shortly reminded in the next section.

\section{Some Problems in ITS and in Instructional Technology Research}

ITS research on knowledge representation so far has concentrated mainly on procedural knowledge, as opposed to declarative; cognitive modeling is often 
conducted from a naturalistic point of view. Authoring of ITS can be said fragmental [13]. ITSs have also been a research focus for years in Instructional Technology (IT), a field close to AIED, with the modeling of instructional design knowledge in authoring environments [14,15,16], or in an instructional design workbench [17].

An analysis of the existing in terms of components shows that few environments combine authoring tools and knowledge representation of instructional theories and principles, and that none of them possesses desired functionalities of an intelligent authoring system such as Retrieve appropriate theories for selecting instructional methods or Provide principles for structuring a learning environment.

Declarative knowledge is mainly absent in those systems, as is the maintenance of its integrity. OE has the potential to solve these problems by proposing a declarative knowledge modeling approach $[18,19,20]$; as a result, the semantic-based knowledge systematization could provide a gateway to learning objects and their management [21]. Instructional Design theories provide the principled knowledge to make high level design decisions such as instructional strategies [22], or to orient the lower level decisions such as learning material. However, tackling the systematization of instructional knowledge is not without major challenges; the two next sections will describe some of these challenges.

\section{Collaborative Ontological Engineering of Instructional Design Knowledge: Challenges of such an Enterprise}

The ontological engineering process was conducted collaboratively by an OE expert and an ID expert. Among the many hallenges of this enterprise are the following questions:

?? should a unification or an integration of theories be a goal, given that theories have competitive or complementary views?

?? should a unification or an integration of theoretical and practical knowledge be a goal, given that such a view is far from available and even questionable?

?? by which criteria should we consider theoretical knowledge? Experimental evidence versus hypothetical or speculative? classical versus emerging?

?? how can a common terminology be found and become acceptable by sometimes divergent theoreticians and practitioners?

?? how to distinguish Learning Theories from Instructional Theories from Instructional Design Theories, when the many classifications available show serious variations and strong overlaps?

?? how to specify these theories when, again, the many classifications of these show serious variations and strong overlaps?

?? how to respect the integrity of each theory vs to integrate theories as questioned by Mayer [23] or Wasson [1]?

?? how to link theoretical to practical knowledge?

?? how to distinguish between domain and task ontologies and to link both in the case of an ontology-based ITS authoring system?

?? what kind of attributes can be given to things when these things are theories? Cognitivist/constructivist? Validated/emergent? 
A very particular question was raised: what should be the status of instructional design knowledge, domain or task knowledge? The following section describes the exploration that was conducted based on Gibbons' view of instructional technology as a design science.

\section{Gibbons' Exploration into Instructional Technology Knowledge}

The issue of considering ID knowledge as domain knowledge or task knowledge is whether to build it into the domain or into the task ontology; considering it as science means engineering the ID knowledge under domain knowledge. For this reason, the work of Gibbons on Instructional Technology (IT) as a design science was given special attention. What is Instructional Technology? The Association for Educational Communications and Technology (AECT) states: "Instructional Technology is the theory and practice of design, development, utilization, management and evaluation of processes and resources for learning." (www.aect.org). IT is composed of two main components: Instructional Design and Instructional Development [24]. Gibbons views IT as a design science in the sense of Simon [25], and attempts to relate theoretical knowledge to practical knowledge as done in the field of industrial design [26]. Classes of technological knowledge are proposed: 1) Fundamental Design Concepts (Operational Principle, Normal Configuration), 2) Criteria and Specifications, 3) Theoretical Tools, 4) Quantitative Data, 5) Practical Considerations, 6) Design Instrumentalities. As an example, a 'normal configuration' is defined as 'the general shape and arrangement that are commonly agreed to best embody the operational principle. Should these classes apply to IT Instructional design's operational principle could be: to build an instructional system that sustains and fosters the learning process, ensures the quality and the effectiveness of learning. This view has the potential to provide a framework for specifying IT knowledge, and stimulates reflection about the actual status of IT knowledge. For example, ID principles are defined as follows by Merrill [27]: a) a principle is a relationship that is always true under appropriate conditions, b) fundamental principles for instructional design do exist, c) these design principles apply regardless of the instructional program or practices involved, d) violating them results in a decrement in learning and performance. Given this definition, ID principles could be considered as 'Operational principles' in the sense of Gibbons.

Further considerations relate to the basic principles of knowledge systematization as they apply to the systematization of theoretical knowledge, and of multiple theories for the same field.

\section{Knowledge Systematization of Theoretical Knowledge}

Knowledge systematization has been done for human consumption to date. The results have mainly been described in natural language in the form of a book or a paper. It might be no problem if humans learn them. But, it becomes a problem when we try to make computers understand and use the knowledge. Knowledge 
systematization for computer-consumption from engineering point of view should enable a seamless flow of knowledge from theoretical world to practical world.

Our systematization project is done not for the sake of theory but for using the theory. By this, we mean that theories should be interpreted from an engineering point of view. Engineering is heavily based on the requirements of practice. For example, a head of a company might want to train some specific competencies/skills such as creative thinking, reasoning in an abstract space, negotiation in sales activities, planning, presentation, etc. of employees who have various background and experiences from novice to expert. Because of the variety of learning goals (competencies and skills) and of the heterogeneity of learners, a variety of theories can help the learning process. For example, although situatedness has been claimed to be one of the most critical factors in successful learning, it is not always considered that way in training practice. Human Resource Development divisions have identified that a skill which is too much specialized for a specific situation or domain to be applied to many situations is not what they need. Instead, what they need are skills which prove to be effective in many situations, that is, competencies. Needless to say, they never want too abstract knowledge which is hard to apply to real world situations, but at the same time, they also dislike inflexible skills which apply only in a specific situation. Another example is social interaction. Some learning theorists claim that social interaction is the essence of learning process; however, for a company which wants to train their employees' reasoning capability in an abstract space or their motor skills, social interaction may seem of little importance.

In short, contrary to the claim of some learning theorists that "this is the only learning theory which explains the learning process", the fact that a variety of learning theories exist may be viewed in a positive way. There exists a variety of requirements for effective learning, and each of them needs a most suitable theory and needs to be interpreted in the terms used in the application domain. Having a collection of the existing theories in an authoring system also allows to respond to the preferences of the instructional designers/authors and of their clients. Moreover, it might prove to be a stimulus to a reflective process on the side of the designers/authors as they consider the potential and relevance of each theory and the compatibility among them, eventually resulting in an improved level of quality. For these reasons, useful characterization of each theory is what we need from an engineering point of view.

When the enterprise is knowledge systematization, the necessary characteristics that systematized knowledge is expected to have are the following: 1) Concepts found in all the knowledge are clearly defined, 2) Concepts are organized in an is-a structure, 3) Dependencies and necessary relations among concepts are explicitly captured, 4) Each viewpoint used for structuring knowledge, if any, is made explicit, 5) Ready for multiple access, 6) Consistency is maintained. The above clearly shows that $\mathrm{OE}$ does contribute to the systematization of knowledge. Furthermore, when the user of the systematized knowledge is an engineer or a designer, which is our case, the set of viewpoints has to include practical points of view. One of our research goals is to make theories available for engineers and for designers/authors of ITSs. 


\section{Ontological Engineering, a Deconstructionist Approach}

For an instructional scientist, OE starts with the deconstruction of the existing body of knowledge, both theoretical and practical. Although a risky enterprise, it is worth the journey. Needless to say, this restructuring process should not be considered a substitute to theory building. A simplified description of the OE process for Level 1 is: 1) Extract most essential concepts and most essential links among them; 2) Define them by their meaning, their attributes, and the semantic constraints on them. Ontological categories for a process are generally: actor (subject, thing which does actions), behaviour (verb, action, phenomena), object (thing being processed by actor), goal (state to be achieved), situation (context in which an action is done) and attributes (characteristics; of all of the above).

The first assumption is that "everything is concrete", and that concrete is defined as dimensioned by time and space.

The second assumption is that we have two kinds of worlds: 1) Concrete worlds (learning, instruction, instructional design) that we describe based upon the best possible approximation of what is existing, 2) Abstract worlds (learning, instruction, instructional design) where we reflect existing theories with the best possible fidelity. These are called Worlds of theories.

Fig. 1 Abstract and concrete worlds and how they relate to each other.

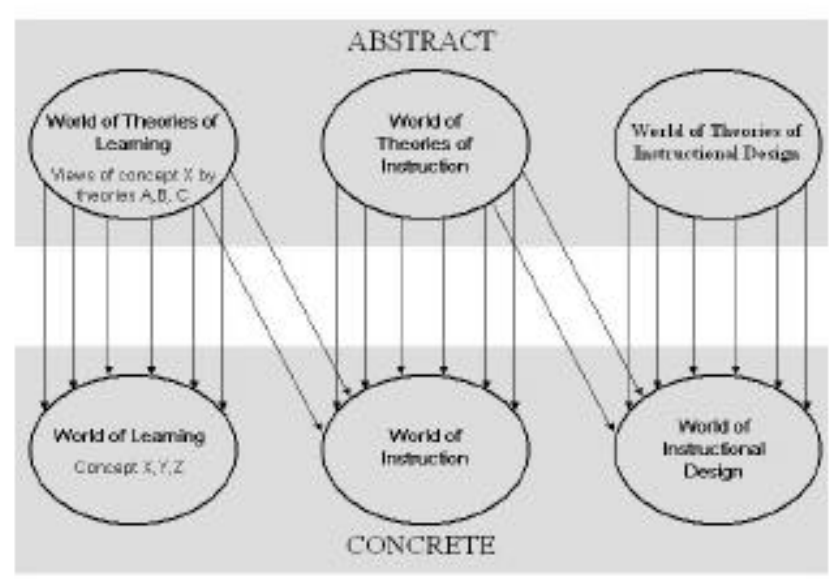

The

third assumption is that we have two ontologies: 1) Domain ontology consists of the worlds of learning, instruction, instructional design, and of the worlds of learning theories, instructional theories, instructional design theories, 2) Task ontology consists of the context of use (by end-user and/or by intelligent system), i.e. the task of designing/authoring (ID task) or the sub-task of authoring (developing).

The fourth assumption is that theories are "things" in the world of theories: 1) Theories of learning, of instruction, of instructional design, 2) Theories of knowledge (epistemologies) on which theories of learning rely, 3) The worlds of theories is part of the Domain Ontology.

Definitions of the theoretical knowledge considered are: 1) A theory of learning is a conceptual system to describe, explain, predict and study natural phenomena involved in the learning process, 2) A theory of instruction is a conceptual system to 
describe, explain, predict and study artificial activities for supporting, organizing, fostering, facilitating, accelerating or evaluating the learning process, 3) A theory of instructional design is a conceptual system to describe, explain, predict and study the design of artificial activities for supporting, organizing, fostering, facilitating, accelerating or evaluating the learning process. Figure 1 illustrates a view of how the three worlds of theories relate to the three concrete worlds.

One of the difficulties that we had in building ontologies of these theories is how to differentiate the relations and constraints contained in an ontology from those in the target theory, since an ontology itself is a theory of existence by definition and hence contains relations and/or constraints among objects just like a target theory is a set of relations/constraints among objects in the target world. We resolved this issue by giving each theory a primary identity with full relations/constraints it needs. Considering the fact that a theory tries to explain its target world we came up with a framework of our ontology building enterprise as shown in Fig. 2. It shows a nested structure of Learning, Instruction, and Instructional Design worlds. Each of the three kinds of theories explains processes/events which happen in each world. One of the major differences among the three kinds of processes/events is that while the lower two are real world processes/events, the other is a planning or design process. A theory needs to refer to objects existing in the target world when it tries to say something about them, which suggests that a theory may have its own set of objects, since any object in a theory is obtained according to the theory-specific articulation of the target world. In fact, a learning theory uses its own way of describing the learning process from its particular view. Each theory has its own viewpoint from which it views the target world. Although these distinctions are not perfect but questionable, they seem reasonable enough to serve the purpose of this work.

A tentative portrait of an ontology of instructional design was then sketched, following the steps recommended by the OE methodology for Level 1: a structured collection of terms, articulation of the world of interest, elicitation of concepts and of the $i s$ - $a$ hierarchy among them.

\section{Portraiting Domain and Task Ontologies of Instructional Design}

A preliminary portrait of ID knowledge provides the main terms to be considered and how they can be structured. Three worlds compose the domain ontology, and two worlds the task

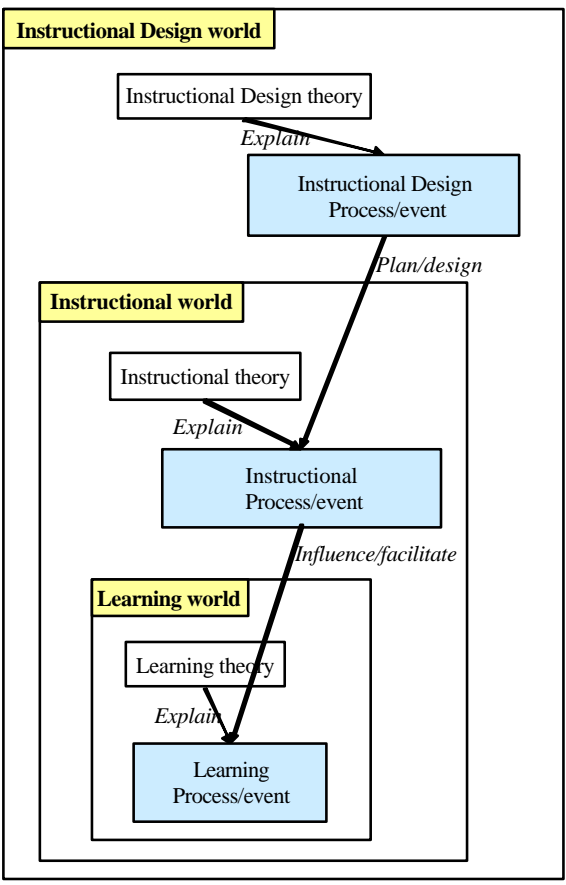
ontologies. A structured collection of 
theories of learning and instruction is provided by Kearsley as an hypermedia base [28]. A view of learning theories from an ID perspective is found in Ertmer and Newby [29]. How Learning Theories view Learning is inspired from Mayer [23].

For the world of learning, the main concepts could be: learning activity, assignment, reading, interacting, problem-solving, learning phase, learning difficulties/remediation. For the world of theories of learning, the main concepts could be: theory of learning, epistemological ground, taxonomy, learning, motivation, attention, comprehension, memory, cognition, meta-cognition, learning phase, learning difficulties/remediation.

For the world of instruction, the main concepts could be: instruction, learning, instructional strategies, teaching, tutoring, assessment of learning. For the world of theories of instruction, the main concepts could be: theory of instruction, theory of learning, epistemological ground, taxonomy, learning, instructional strategies, teaching, tutoring, assessment of learning.

For the world of instructional design, the main concepts could be: instructional design, instruction, learning, instructional scenario, learning environment, selection of methods, selection of media, selection of assessment methods. For the world of theories of instructional design, the main concepts could be: theory of instructional design, theory of instruction, theory of learning, epistemological ground, taxonomy, learning, selection of methods, selection of media, selection of assessment methods.

As a conclusion to this preliminary portrait of knowledge relevant to the OE of ID knowledge, it is obviously too early to say whether these distinctions will reveal valuable; it is anticipated that a series of iterations may be needed before a satisfactory collection of terms is found.

\section{Building these Ontologies into the Ontology Editor}

The building of these ontologies into the Ontology Editor* fulfills the Level 1 of OE, and exposes the links and the hierarchy to constraint checking. Essentially, the building process consists, besides consolidating the terms and the hierarchy, in the specification of $I s-a$ and Part-of relationships for each term. Generate and test is the preferred method, until a reasonable structure is obtained, and until all the constraints are fully respected. Another ontological category to be considered is role, as it proved to be a quite useful one in our case:

a) Instructional designer is a role (agent of design), with, as sub-roles, analyst of learning contents, of learners' characteristics, of learning context; designer of scenarios, of learning environments; developer of learning environments; collaborator with other designers, etc.

b) Instructor is a role (agent of instruction), with, as sub-roles, information presenter; discussion moderator; asking questions/answering questions; asking for/giving explanation; solving problems; collaborate; assess learning; game master; organizing lab experiment/field experiment; organize simulation/role play, etc.

c) Learner is a role (agent of learning), with, as sub-roles, asking/answering questions; asking for/giving explanation; solve problems; play simulation games; make assignments; pass examinations; self-manage learn ing; self-assess learning, etc. 
An extract of the building within the Ontology Editor is shown in Fig. 3.

Figure 3. Extract of the ontology built within the Ontology Editor

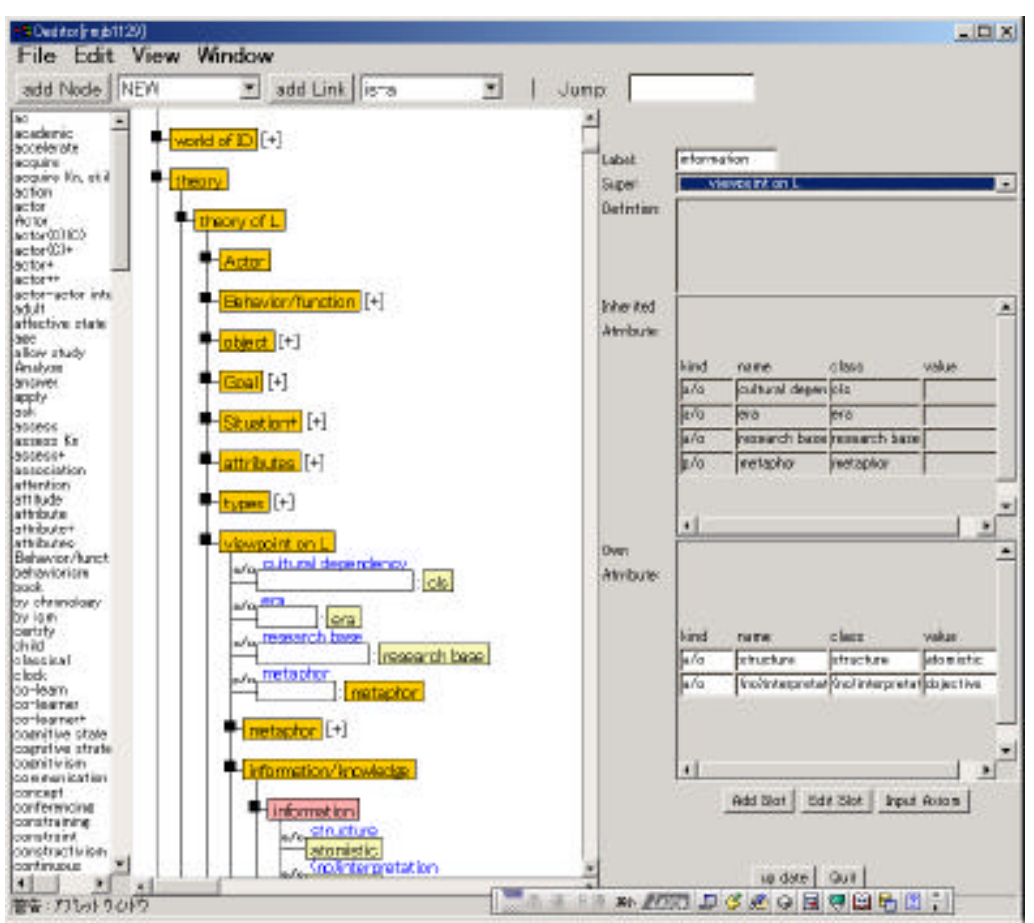

\section{Further Work}

The work towards a Level 1 of the ontology needs to be completed, in that the collection of terms must be stabilized, the hierarchy also needs to be stabilized, the relations need to be completed and refined, the definitions need to be completed, the semantic constraints need to be fully checked. A series of iterations is expected to be necessary to obtain a satisfactory Level 1 .

Further steps on our roadmap include:

1) Produce two detailed examples. Based on the assumption that "everything is concrete", and that "concrete" means "dimensioned by time and space", we plan to illustrate this idea with two concrete examples, specified within the Ontology Editor: Learner-Instructor interaction (what is it made of? Specify components and roles), Scenario building (what is it made of? Scenarize the desired functionalities).

2) Elaborate functionalities of an ontology-based ITS authoring system. The functionalities of such a system can be: Intelligent theory retriever, Intelligent navigator based on theories, Advisor to form an appropriate collaborative learning group, etc. Steps towards the identification of these functionalities are: 1) imagine what users can do with an ontology-aware authoring environment, 2) specify new 
functionalities, 3) build a scenario-based demo of functionalities, 4) test mockup and validate with users.

A long term perspective for this work is to provide the next generation of authoring systems with a scientific basis for semantic standards of learning objects and their management.

\section{Concluding Remarks}

We have presented a work in progress in AIED research that aims at -ontologyawareness for future ITS authoring systems. Collaborative ontological engineering of ID knowledge has been described, followed by the first results on a road map towards an ontology-aware authoring system.

The implications of "ontology-awareness" are meaningful, not only for AIED research into system building but also for knowledge sharing between humans and computers. OE enables humans to share theories with computers, and stimulates the quest for a consensus among humans. If an ontology represents a shared conceptualization in a community, $\mathrm{OE}$ has the potential to contribute to the building of such a conceptualization.

Discussions about the hierarchical nature of ontologies can help find general concepts by going up the hierarchy. The is- $a$ and part-of hierarchies help humans in finding the essential differences between them. The first results described above represent a possible shared conceptualization. It may be far from complete, but it should provide a good start to come up with a richer agreement.

*The Ontology Editor was developed at Mizlab, Osaka University ( http://www.ei.sanken.osaka-u.ac.jp/oeloe.html).

\section{References}

[1] Wasson, B. (1996). Instructional Planning and Contemporary Theories of Learning, In P. Brna, A. Paiva \& J. Self (Eds.). Proc. of the Eur. Conf. on AIED, 23-30, Lisbon: Colibri.

[2] Nkambou, R. Gauthier, R., and Frasson, C. (1996). CREAM-tools: An authoring environment for curriculum and course building in an ITS. Proc. of the $3 d$ Int'l Conf. on CAL \& Inst'l Sc. \& Eng, NY: Springer-Verlag.

[3] Kay, J. (2000). Accretion Representation for Scrutable Student Modelling, Proc. ITS'2000, 514-523.

[4] McCalla G., Vassileva, J., Greer, J. and Bull, S. (2000). Active Learner Modeling, Proc. ITS'2000, 53-62.

[5] Goodyear, P. (1991). Teaching Knowledge and Intelligent Tutoring. Norwood, NJ: Ablex.

[6] Granbastien, M. (1999). Teaching Expertise is at the Core of ITS Research, IJAIED, 10, 335-349.

[7] Baker, M. (2000). The roles of models in AIED research: a prospective view. IJAIED, 11 (2), 122-143.

[8] Katz, S., O'Donnell, G. and Kay, H. (2000). An approach to analyzing the role and structure of reflective dialogue, IJAIED, 11, 320-343. 
[9] Lajoie, S.P., Faremo, S. and Wiseman, J. (2001). Identifying human tutoring strategies for effective instruction in internal medicine. IJAIED, Special Issue on Modelling Teaching.

[10] Andriessen, J. and Sandberg, J. (1999). Where is education heading and how about AI? IJAIED, 10, 130-150.

[11] Brusilovsky, P. (2000). Course Sequencing for Static Courses? Applying ITS Techniques in Large-Scale Web-based Education, Proc. ITS'2000, 625-634.

[12] Mizoguchi, R. and Bourdeau, J. (2000). Using Ontological Engineering to Overcome Common AI-ED Problems. IJAIED, Special Issue on AIED 2010, vol.11, 107-121. http://cbl.leeds.ac.uk/ijaied/

[13] Murray, T. (1999). Authoring intelligent tutoring systems: an analysis of the state of the art, IJAIED, 10, 98-129.

[14] Merrill, D. (1993). An integrated model for automating instructional design and delivery, in Spector, M., Polson, P. and Muraida, D., eds.. Automating Instructional Design: Concepts and Issues, Engl. Cliffs, NJ: Educational Technology.

[15] Spector, M., Polson, P. and Muraida, D., eds., (1993). Automating Instructional Design: Concepts and Issues, Engl. Cliffs, NJ: Educational Technology.

[16] Tennyson, R. and Barron, A., Eds. (1995) Automating Instructional Design: ComputerBased Development and Delivery Tools. Springer, NATO ASI Series, Series F: Computer and Systems Sciences, vol. 140.

[17] Paquette, G. (2001). Telelearning Systems Engineering -Towards a New ISD Model, Jl of Structural Learning and Intelligent Systems, 14 (4), 319-154.

[18] Mizoguchi, R. and Sinitsa, K. (1996) Architectures and Methods for Designing CostEffective and Reusable ITSs, Proc. ITS'96, Montreal, pp. 1-21.

[19] Ikeda, M., Seta, K., and Mizoguchi, R. (1997) Task Ontology Makes It Easier To Use AuthoringTools. Proc. of IJCAI-97, Nagoya, Japan, 342-347.

[20] Chen, W. Hayashi, Y., Kin, L. Ikeda, M. and Mizoguchi, R. (1998) Ontological Issues in an Intelligent Authoring Tool, in Chan T-W., Collins A. \& Lin J. (Eds.), Proc. of ICCE'98, vol. $1,41-50$.

[21] Wiley, D. (2001). Instructional Use of Learning Objects. Bloomington, Indiana: The Agency for Instructional Technology.

[22] Jones, M. (1988). Instructional Systems Need Instructional Theory: Comments on a Truism. Paper presented at the NATO Research Workshop "New Directions in Education Technology", Cranfield, England, November 10-13. (Tech. report, ARIES Lab., U. of Saskatchewan).

[23] Mayer, R. (1997). Learners as information processors. Educational Psychology Journal, $31(3 / 4), 151-161$.

[24] Seels B. and Richey R. (2001). Instructional Technology: The Definition and Domains of the Field. Washington, DC: AECT.

[25] Simon, H. (1969). The Sciences of the Artificial. Cambridge, MA: MIT Press.

[26] Gibbons, A. (2000). The Practice of Instructional Technology. Presented at the 2000 AECT conference, $48 \mathrm{p}$.

[27] Merrill, D. (1994). Instructional Design Theories. Engl. Cliffs, NJ: Ed. Tech. Publications.

[28] Kearsley, G. Explorations in Learning \& Instruction: The Theory Into Practice Database. http://tip.psychology.org/

[29] Ertmer, P. A., Newby, T. J. (1993). Behaviorism, cognitivism, constructivism: Comparing critical features from an instructional design perspective. Performance Improvement Quarterly, $6(4), 50-70$.

Credits. This work was supported by ISIR, Osaka University, where the first author spent a three month invited stay, Sept-Dec. 2001. 